294

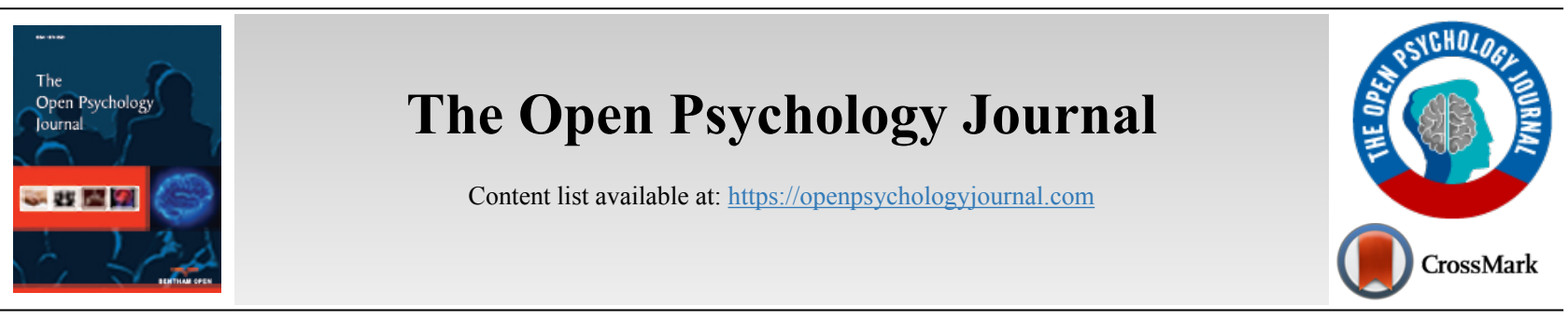

RESEARCH ARTICLE

\title{
The Relationship Between Daily Hassles and Social Support on Depressive Symptoms among Mothers of Young Kids
}

\author{
Nur Asyikin Yakub ${ }^{1, *}$, Nor Ba'yah Abdul Kadir ${ }^{1}$ and Suzana Mohd Hoesni ${ }^{1}$ \\ ${ }^{l}$ Center for Human and Societal Well-Being, Faculty of Social Sciences and Humanities, National University of Malaysia, Bangi, Malaysia
}

\begin{abstract}
:
Introduction:

The aim of this paper is to determine the relationship between the common factors of mothers' depressive symptoms based on the existing literature, including the current happenings within Malaysians.

Methods:

This study involved mothers from four community housing projects around Kuala Lumpur ( $\mathrm{n}=146)$, and with consent, they were asked to complete a questionnaire, which included the following three instruments: Parenting Daily Hassles Scales, Social Support Scales, and Beck Depressive symptoms Inventory to measure all stated variables in this study.

Results and Discussion:

The results of the study showed the significant relationship between the daily hassles (DH) and social support (SS) towards the depressive symptoms among the mothers, $\mathrm{DH}, \mathrm{r}=.272, \mathrm{p}=.001$ and $\mathrm{SS}, \mathrm{r}=-.230, \mathrm{p}=.006$. Further analysis was consummated to determine the factors that could influence the depressive symptoms among mothers and the contribution of variance towards that. From the analysis, DH and SS contributed $13.9 \%$ of the variance (Adjusted $\mathrm{R}^{2}=.139$ ) and were found to influence the depressive symptoms among the mothers.

Conclusion:

The ANOVA test analysis supported the earlier study that the daily hassles and social support statistics significantly predict the depressive symptoms among mothers. In conclusion, this study should be broadedned to a bigger community, and future efforts as an early intervention on health promotion are essential to strengthen social support by reducing stressors effect that contributes to mental health problems in mothers of young kids.
\end{abstract}

Keywords: Daily hassles, Social supports, Young kids, Depressive symptoms, Mothers, Mental health.

\begin{tabular}{|l|l|l|r} 
Article History & Received: February 12, 2021 & Revised: May 07, 2021 & Accepted: May 30, 2021
\end{tabular}

\section{INTRODUCTION}

Decades of research has shown that depression becomes a serious mental health problem globally that can negatively affect the individual's life [1], and family institution [2]. Vulnerable factors have been studied on how individuals develop depression, and it has been agreed that gender differences occurred in how individuals are exposed to interpersonal life events [3]. Women reported being more exposed with interpersonal life events compared to men [4]. Therefore, the mothers reported a double risk of developing

* Address correspondence to this author at the Center for Human and Societal Well-Being, Faculty of Social Sciences and Humanities, National University of Malaysia; Tel: 0172377802; E-mail: syikinyakub@gmail.com depression in life [5 - 7]. It is more imperative for those living in disadvantaged circumstances $[2,8,9]$ and facing serious, difficulty in daily hassles of parenting $[6,10,11]$.

Few studies clearly discussed how stressful daily hassles associated with the child characteristics, such as temperament $[10,12-15]$ and poor child health that lead mothers to experience depression over the lifetime in adaptation to parenthood. Moreover, mothers in early marriage with younger kids $[15,17,18]$ face a substantial challenge in raising a family due to a lack of experienced and adaption skills to parenthood $[19,20]$. Several studies have pointed out that mothers with younger kids were highly reported having depression in comparison with people without kids $[6,18,21]$. 
Previous studies have shown that social support is an undeniable factor that is associated with depression among mothers. Social support refers to the perceived comfort, caring, esteem, or help a person receives from different sources, such as spouse or lover, family, friends, work colleagues, or community organizations [22]. Research among Malaysian women indicated that mothers, who suffer from depression have poorer spouse social support and feel a lack of love [23]. According to Respler-Herman, Mowder, Yasik, and Shamah [24], the high social support received individually among mothers and fathers indicated a positive parenting experience. Thus, receiving social support from the spouse, friends, and other family members is essential, as it reflects stress reduction, which leads to the reduction of depression risk [25, 26].

Other concerns on depressive symptoms among parents, the past Western researchers have given more attention to the extent of the causes of raising abnormal child [27 - 29], and the same goes for Malaysia [30]. It is evident that raising children with mental retardation, autism, and other forms of developmental challenges increase the hassles and depressive symptoms among parents due to high demands and encounters of parenting [31 - 36]. Nevertheless, higher rates of mothers' depression occurred due to the existence of multiple stressors in the family and likewise in raising a normal kid [6, 37, 38].

Thus, the researcher found the importance of reporting the association between the common factors that affect the presence of the mothers' depressive symptoms, which are daily hassles and the social support among the Malaysian mothers' population. Furthermore, the risk increases for mothers with young kids. Therefore, three hypotheses were carried out in this study which are as follows:

1) There is a relationship between daily hassles and depressive symptoms among mothers of young kids.

2) There is a relationship between social support and depressive symptoms among mothers of young kids.

3) Daily hassles and social support could influence depressive symptoms of mothers having young kids.

\section{METHODS}

\subsection{Participants}

This study employed 146 mothers from four community housing projects around Kuala Lumpur, who belonged to a lower socioeconomic class. Their age was between 19 to 40 years. They were recruited randomly from a family weekend program at the community hall. The data collection method used was a self-administered questionnaire written in the Malay Language. The consent of the confidentiality of personal identification and participant information sheet was given along with the questionnaire. They were requested to complete the questionnaire on the same day. It consists of mother's sociodemographic data such as their age, employment status, monthly household income, numbers of children in the family, and the age of their kids, as well as other variables to test out the hypotheses of the study, which involved their mental health well-being on depressive symptoms, parenting daily hassles and perceived social support.

\subsection{Instruments}

The questionnaire included the following three instruments: Beck Depression Inventory (BDI), Parenting Daily Hassles Scales (PDHS), and Social Support Scales (SSS).

Beck Depression Inventory (BDI), having 21 items, was developed specifically to assess the overall prevalence and severity of depressive symptoms among adults. Participants responded to questions in relation to how they have felt over the past week, with higher scores indicating more severe depressive symptoms. BDI has been used widely and has reported high internal consistency with Cronbach's alpha $=.93$ [39]. The earlier study on validity and the reliability of the Malay version of BDI also reported high internal consistency, Cronbach's alpha $=0.88$ [40].

Parenting Daily Hassles Scale (PDHS), having 20 items, which is designed for parents of young kids, aimed to assess the minor parenting stresses within the context of parent-child relationships [10]. All the 20 potential hassles contained the challenging typical everyday behavior and the parenting tasks, such as feeling irritated, frustrated, annoyed, and distressed that to some degree characterize everyday transactions with the environment, which were then associated with the mothers' responding irritably to her child. The mothers were asked to rate the frequency on a Likert scale, 4-point scale (rarely, sometimes, a lot, constantly), and how much they were irritated or hassled by the event (on a 5-point scale, from not at all to a great deal). This PDHS produces two scores, a frequency and an intensity score, which were highly correlated. The challenging behaviour total score is obtained by adding the intensity scale scores for items: $2,4,8,9,11,12,16$ with range: $0-35$, whist, the parenting tasks total score is obtained by adding the intensity scale scores for items: $1,6,7,10,13,14$, 17, 20 with range: $0-40$. There is no cut-off for any of the scales, but total scores above 50 on the frequency scale or above 70 on the intensity scale indicate a frequency of potentially hassling happenings and reflect the parents' experiencing significant pressure over parenting. The reliability of these scales is acceptable, with alpha coefficients of .81 and .90 , respectively [41].

Social Support Scales (SSS) having 6 items is an adaptation from the brief Social Support Scales by Sarason et al. that assess the level of social support received among adults. This indicates the person who provide support to the individuals and by shares their sadness and difficulties that occurred in certain circumstances. For each item, mothers were asked to rate the needed support and the frequency of the three persons (e.g., spouse, family member, friend, or close relative) during difficulties in life. The high score indicates high social support received by themselves.

\subsection{Statistical Analysis}

The data were analyzed using SPSS version 25.0. With regards to measuring the relationship of the variables studied, the Pearson Correlation was used, and the strength of the relationship was determined. Further analysis was done using 
the ANOVA to test the predictors and the contribution of variance towards the dependent variable of this study. The results were used to support the three hypotheses in this study. All the results were presented in the result section.

\subsection{Ethics Approval}

This study went through the ethics approval prior to the survey started. This study was approved by the research ethics committee of The National University of Malaysia with approval number JEP-2018-076.

\section{RESULTS}

The mean age of the 147 mothers is $29.49(\mathrm{SD}=4.98)$, with a range age of 19 to 40 years. On average, the mothers were currently raising 2 children $(\mathrm{SD}=.88)$. The mean age of children is $6.36(\mathrm{SD}=3.33)$, with a range of 6 to 9 years. Out of the mothers having living in the socio-economic disadvantage, more than half of the mothers $(61.6 \%)$ were housewifes and others were working either as government or private employees. The majority of the participants, 93.8\%, reported their monthly household income below RM2000. The summary of the demographic data was presented in Table $\mathbf{1 .}$

Table 1. The socio-demographic summary of the mothers.

\begin{tabular}{|c|c|}
\hline Characteristic & $\mathbf{n}=\mathbf{1 4 6}$ \\
\hline Mean age, year (SD) & $30.52(5.98)$ \\
\hline Mean number of children (SD) & $2.22(0.88)$ \\
\hline Mean age of children (SD) & $6.36(3.33)$ \\
\hline Family income (\%) & 93.8 \\
Below RM 2000 & 6.2 \\
Above RM 2000 & \\
\hline
\end{tabular}

The descriptive analysis reports the level of depressive symptoms, the intensity, and the frequency of daily hassles, as well as the social support received by the mothers. Table 2 shows the descriptive statistics of the measured variables.

Table 2. The frequencies of the level, mean and standard deviation of depressive symptoms, daily hassles and social support among the mothers $(n=146)$.

\begin{tabular}{|c|c|c|c|c|c|}
\hline Variable & \multicolumn{2}{|c|}{ High } & \multicolumn{2}{|c|}{ Low } & Total Score \\
\hline- & $\mathbf{n}$ & $\%$ & $\bar{n}$ & $\%$ & (Mean/SD) \\
\hline Depressive symptoms & 36 & 24.7 & 110 & 74.3 & $\begin{array}{c}8.33 \\
(8.203)\end{array}$ \\
\hline $\begin{array}{c}\text { Frequency of the challenging } \\
\text { behavior }\end{array}$ & 12 & 8.2 & 134 & 91.8 & $13.46(3.827)$ \\
\hline Frequency of parenting tasks & 21 & 14.4 & 125 & 85.6 & $15.27(5.089)$ \\
\hline $\begin{array}{l}\text { Intensity of the challenging } \\
\text { behavior }\end{array}$ & 45 & 30.8 & 101 & 69.2 & $37.28(10.102)$ \\
\hline Intensity of parenting tasks & 49 & 33.6 & 97 & 66.4 & $36.66(12.612)$ \\
\hline Social support & 65 & 44.5 & 81 & 55.5 & $16.85(15.272)$ \\
\hline
\end{tabular}

Table 2 shows the frequencies of the level, mean and standard deviation of depressive symptoms, daily hassles, and social support among the mothers. The indicators are divided into two categories; low and high. The division of the categories for each variable is divided by the total scores of the indicators by two to set up the cut-off scores. The high scores for the depressive symptoms indicate the high level for the first division, and lower scores indicate the low-level division and same goes for the subscales of DH; high scores of the division indicate the high frequency and the intensity of the challenging behavior and the parenting tasks, whilst the lower scores indicate the low frequency and intensity. The SS total scores through the same calculation as depressive symptoms indicators and the high level of SS indicated the high support and vice versa.

From the number of participants, $110(74.3 \%)$ reported a low level of depressive symptoms, and the other $36(24.7 \%)$ reported facing a high level of depressive symptoms $(\mathrm{M}=8.33$, $\mathrm{SD}=8.203$ ). For daily hassles, two categories of frequency and intensity of the hassles were determined, the challenging behavior and parenting tasks. Both found a high number of participants reporting a low level of frequency and intensity, frequency of challenging behavior $134(91.8 \%)$, frequency of parenting tasks $125(85.6 \%)$, and intensity of challenging behavior $101(69.2 \%)$, the intensity of parenting tasks 97 (66.4\%), compared to the number of a high level of frequency and intensity, frequency of challenging behavior $12(8.2 \%)$, frequency of parenting tasks $21(14.4 \%$, and intensity of challenging behavior $45(30.8 \%)$, the intensity of parenting tasks $49(33.6 \%)$. The mean total score for the frequency and the intensity are as follows: frequency of challenging behavior $(\mathrm{M}=13.46, \mathrm{SD}=3.827)$, frequency of parenting tasks $(\mathrm{M}=$ $15.27, \mathrm{SD}=5.089)$ and intensity of challenging behavior $(\mathrm{M}=$ $37.28, \mathrm{SD}=10.102)$, intensity of parenting tasks $(\mathrm{M}=36.66$, $\mathrm{SD}=12.612$ ), whilst, for the social support, more than half of the mothers $(55.5 \%)$ reported perceived low-level social support compared to the respondents, who reported high support $(44.5 \%)$ with the total mean score $(\mathrm{M}=16.85, \mathrm{SD}=$ 15.272).

With regards to testing the hypotheses of the current study, the Pearson Correlation was used to measure the relationship that occurred between the variables. The analysis result is presented in Table 3 .

Table 3. The relationship between depressive symptoms, daily hassles and social support among the mothers $(n=$ 146).

\begin{tabular}{|c|c|c|}
\hline Variables & \multicolumn{2}{|c|}{ Depressive symptoms } \\
\hline & $\mathrm{r}$ & Sig. \\
\hline Daily Hassles & $.272^{* *}$ & .001 \\
\hline Social Support & $-.230^{* *}$ & .001 \\
\hline ** Correlation is significant at the 0.01 level (2-tailed).
\end{tabular}

Hypothesis 1: There is a relationship between daily hassles and depressive symptoms among mothers of young kids.

The Pearson correlation was conducted (Table 3), which showed positive significant correlation between the daily hassles and depressive symptoms among mothers $(r=.272, \mathrm{p}<$ 0.01 ), which indicated that higher the daily hassles, the higher the depressive symptoms occurred among the mothers. Therefore, hypothesis 1 (there is a relationship between daily hassles and depressive symptoms among mothers of young kids) is accepted.

Hypothesis 2: There is a relationship between social support and depressive symptoms among mothers of young kids. 
A similar analysis was done to test the correlation between social support and depressive symptoms among the mothers. Results showed that social support was negatively significantly correlated with the depressive symptoms among mothers $(\mathrm{r}=$ $.230, \mathrm{p}<0.01)$. It means that lower the social support received by the mothers, the higher the depressive symptoms among the mothers. Therefore, hypothesis 2 (There is a relationship between social support and depressive symptoms among mothers of young kids) is accepted.

Further analysis was done using ANOVA to test the possible predictors that could influence the depressive symptoms and the contribution of variance towards the dependent variable of this study. From the analysis in Table 4, the daily hassles and social support were found significant as predictors for depressive symptoms among mothers with a significance value .000 . The amount of variance explained $13.9 \%$ of the daily hassles and social support influencing the depressive symptoms among mothers. With that result, hypothesis 3 (Daily hassles and social support could influence depressive symptoms of mothers having young kids) is accepted.

Table 4. ANOVA to test the predictors of depressive symptoms among the mothers $(n=146)$.

\begin{tabular}{|c|c|c|c|c|c|c|c|c|c|c|c|c|}
\hline \multicolumn{13}{|c|}{ Model Summary ${ }^{b}$} \\
\hline \multirow{2}{*}{\multicolumn{2}{|c|}{ Model }} & \multirow[b]{2}{*}{$\mathbf{R}$} & \multirow{2}{*}{\multicolumn{2}{|c|}{$\begin{array}{c}\mathbf{R} \\
\text { Square }\end{array}$}} & \multirow[b]{2}{*}{$\begin{array}{c}\text { Adjusted } \\
\text { R } \\
\text { Square }\end{array}$} & \multirow{2}{*}{\multicolumn{2}{|c|}{\begin{tabular}{|c|} 
Std. \\
Error of \\
the \\
Estimate
\end{tabular}}} & \multicolumn{5}{|c|}{ Change Statistics } \\
\hline & & & & & & & & $\begin{array}{c}\mathbf{R} \\
\text { Square } \\
\text { Change }\end{array}$ & $\begin{array}{c}F \\
\text { Change }\end{array}$ & df1 & df 2 C & $\begin{array}{l}\text { Sig. F } \\
\text { Change }\end{array}$ \\
\hline & 1 & $.373^{\mathrm{a}}$ & & 139 & 0.127 & 7.77 & & 0.139 & 10.999 & 2 & 136 & 0 \\
\hline \multicolumn{13}{|c|}{$\begin{array}{l}\text { a. Predictors: (Constant), DH, SS. } \\
\text { b. Dependent Variable: Depressive }\end{array}$} \\
\hline \multicolumn{13}{|c|}{ ANOVA $^{a}$} \\
\hline \multicolumn{3}{|c|}{ Model } & \multicolumn{4}{|c|}{ Sum of Squares } & df & \multicolumn{3}{|c|}{ Mean Square } & $\mathbf{F}$ & Sig. \\
\hline \multicolumn{4}{|c|}{ Regression } & \multicolumn{3}{|c|}{1329.97} & 2 & \multicolumn{2}{|c|}{664.985} & & 10.999 & \begin{tabular}{|l|l|}
9 & $.000^{\mathrm{b}}$ \\
\end{tabular} \\
\hline \multirow[t]{2}{*}{1} & \multicolumn{3}{|c|}{ Residual } & \multicolumn{3}{|c|}{8222.56} & 136 & \multicolumn{2}{|c|}{60.46} & & - & - \\
\hline & \multicolumn{2}{|c|}{ Total } & & \multicolumn{3}{|c|}{9552.53} & 138 & \multicolumn{3}{|c|}{-} & - & - \\
\hline
\end{tabular}

a. Dependent Variable: Depressive symptoms.

b. Predictors: (Constant), DH, SS

\section{DISCUSSION}

The result presented in this study indicates that there is a significant relationship between daily hassles and social supports among mothers with young kids. The findings also found the association of the high daily hassles with the high depressive symptoms of the mothers and the lower social support associated with the high depressive symptoms occurred. The findings supported the same results of the earlier research on stressful life events, which reveals that depressive symptoms are higher among the mother of young children due to the exposure of more stressors $[6,15,18]$. The findings regarding the matter of the social support were found similar to that of the previous study that lack of support to the mother of the toddlers correlated with the depressive symptoms $[5,13]$ as well as to the high-risk mothers, such as mothers who are living in poverty [25] and a mother who is raising an abnormal child [42].

One study on early intervention indicated that the social and interpersonal relationship between the children and mother or father might be depleted by the economic hardships of the family, and that the children have to bear the outcomes of this [43]. Thus, it is essential to warn individually on the red flags that parental depression is a powerful risk factor of poor child outcomes [9, 44]. In addition, the mother's depressive symptoms are associated with the greater effect of poorer caregiving behavior and less self-focus [38], however, only a few studies focused on the relation of parental depression to the development of childhood [27].

Even though this study involved most of the preschoolers' kids, however, the children do not yet understand the concrete logic where they should be monitored and assisted with regards to their routine activities, especially in daily routines. This has been explained by the Cognitive Development Stage by Jean Piaget; children with age 2-7 are in the preoperational stage, and one previous study with almost 87000 parents with children aging from 0 to 12 years reported that by the age of $12,39 \%$ of the mothers and $21 \%$ of the fathers had experienced an episode of depression [45]. The findings indicated that parents faced the risk of having depression since the transition to parenthood after the birth of the first child [19]. Furthermore, the worst scenarios where parents of those children who require special attention experience other external factors occurring at the same time that may burden them, predict the increasing risk of depression [46]. To what extent, alternatively, the previous study proposed the intervention needed to enhance, promoting the importance of effective coping strategies in parenthood for reducing the risk of depression among parents $[6,42,43,47]$. The intervention may help, especially the mothers, in increasing their knowledge on parenting skills for the critical early years of their children's lives [9].

Overall, although this study found significance for all the studied variables and all the accepted hypotheses, some limitations must be noted. Firstly, the sample size of this study was small compared to the population of almost 250,000 living in the community housing project in the urban city of Kuala Lumpur. Thus, this current study findings cannot be generalized to the overall population. On the other hand, this study should be benefited to a bigger community. Despite this, the small sample size may affect any part of the result in the study. Second, this study only included the mothers of the family, therefore, the future study should take into consideration the fathers and difference among genders so that the risk of depression could be determined. Last, the sociodemographic factors could be measured to strengthen the framework of the study as well as provide the findings for future research.

\section{CONCLUSION}

The finding of the regression indicated that the daily hassles and social support are significant predictors of depressive symptoms among the mothers. These findings support the earlier researchers' findings that both variables contribute in predicting the depressive symptoms in this population. However, this study has some limitations, such as the low sample size, involvement of mothers within the same area, and no consideration on examining the relationship 
between the demographic profile of the mothers and the variables studied, which should be considered for further improvement. The overall findings of this study provide strong support on the implementation of early intervention on health promotion that is essential for strengthening social support and reducing stressors effect that contributes to mental health problems in mothers of young kids.

\section{ETHICS APPROVAL AND CONSENT TO PARTICIPATE}

This research was approved by the Research Ethics Committee of the National University of Malaysia, Bangi, Malaysia (JEP-2018-076).

\section{HUMAN AND ANIMAL RIGHTS}

No animals were used in this research. All human research procedures were followed in accordance with the ethical standards of the committee responsible for human experimentation (institutional and national), and with the Helsinki Declaration of 1975, as revised in 2013.

\section{CONSENT FOR PUBLICATION}

The participants signed the form as a consent to participate in the study.

\section{AVAILABILITY OF DATA AND MATERIALS}

The data supporting the findings of this study is present within the manuscript.

\section{FUNDING}

None.

\section{CONFLICT OF INTEREST}

The authors declare no conflict of interest, financial or otherwise.

\section{ACKNOWLEDGEMENTS}

We thank all mothers who participated in this research and have provided information for the research.

\section{REFERENCES}

[1] Liu Q, He H, Yang J, Feng X, Zhao F, Lyu J. Changes in the global burden of depression from 1990 to 2017: Findings from the Global Burden of Disease study. J Psychiatr Res 2020; 126: 134-40.

[2] England MJ, Sim LJ. Depression in parents. Parenting, and children 2013.

[3] Hammen C. Stress and depression. Annu Rev Clin Psychol 2005; 1(1): 293-319.

[http://dx.doi.org/10.1146/annurev.clinpsy.1.102803.143938] [PMID: 17716090]

[4] van der Waerden JEB, Hoefnagels C, Hosman CMH, Souren PM, Jansen MWJ. A randomized controlled trial of combined exercise and psycho-education for low-SES women: Short and long-term outcomes in the reduction of stress and depressive symptoms. Soc Sci Med 2013; 91: 84-93.

[http://dx.doi.org/10.1016/j.socscimed.2013.05.015] [PMID: 23849242]

[5] Johansson M, Svensson I, Stenström U, Massoudi P. Depressive symptoms and parental stress in mothers and fathers 25 months after birth. J Child Health Care 2017; 21(1): 65-73.

[http://dx.doi.org/10.1177/1367493516679015] [PMID: 29156983]

[6] Flouri E, Narayanan M K, Nærde A. Stressful life events and depressive symptoms in mothers and fathers of young children. J Affect Disord 2018; 230: 22-7.

[http://dx.doi.org/10.1016/j.jad.2017.12.098]

[7] van der Waerden JEB, Hoefnagels C, Hosman CMH. Psychosocial preventive interventions to reduce depressive symptoms in low-SES women at risk: A meta-analysis. J Affect Disord 2011; 128(1-2): $10-23$.

[http://dx.doi.org/10.1016/j.jad.2010.02.137] [PMID: 20346517]

[8] Edin K, Kissane RJ. Poverty and the American family: A decade in review. J Marriage Fam 2010; 72(3): 460-79.

[http://dx.doi.org/10.1111/j.1741-3737.2010.00713.x]

[9] Williams DT, Cheadle JE. Economic hardship, parents' depression, and relationship distress among couples with young children. Soc Ment Health 2016; 6(2): 73-89.

[http://dx.doi.org/10.1177/2156869315616258] [PMID: 27942421]

[10] Crnic KA, Greenberg MT. Minor parenting stresses with young children development minor parenting stresses with young children. Young Child 2010; 61(5): 1628-37.

[11] Kessler RC. The effects of stressful life events on depression. Annu Rev Psychol 1997; 48(1): 191-214.

[http://dx.doi.org/10.1146/annurev.psych.48.1.191] [PMID: 9046559]

[12] Nomaguchi K, Johnson W. Parenting stress among low-income and working-class fathers: The role of employment. J Fam Issues 2016; 37(11): 1535-57.

[http://dx.doi.org/10.1177/0192513X14560642] [PMID: 27616804]

[13] Saisto T, Salmela-Aro K, Nurmi J-E, Halmesmäki E. Longitudinal study on the predictors of parental stress in mothers and fathers of toddlers. J Psychosom Obstet Gynaecol 2008; 29(3): 213-22.

[http://dx.doi.org/10.1080/01674820802000467] [PMID: 18608816]

[14] Goodman SH, Gotlib IH. Risk for psychopathology in the children of depressed mothers: A developmental model for understanding mechanisms of transmission. Psychol Rev 1999; 106(3): 458-90. [http://dx.doi.org/10.1037/0033-295X.106.3.458] [PMID: 10467895]

[15] Guo N, et al. Mental health related determinants of parenting stress among urban mothers of young children-results from a birth-cohort study in Ghana and Côte d'Ivoire. In: BMC Psychiatry. 2014; 14: p. 156.

[http://dx.doi.org/10.1186/1471-244X-14-156]

[16] Dearer-Deckard K. Parenting stress. Yale University Press 2014.

[17] Manuel JI, Martinson ML, Bledsoe-Mansori SE, Bellamy JL. The influence of stress and social support on depressive symptoms in mothers with young children. Soc Sci Med 2012; 75(11): 2013-20. [http://dx.doi.org/10.1016/j.socscimed.2012.07.034] [PMID: 22910191]

[18] Nomaguchi K, Fettro MN. Center for family and demographic research why do mothers experience more work-family conflict when their children are younger 2016; (419): 1-37.

[19] Halford WK, Petch J. Couple psychoeducation for new parents: Observed and potential effects on parenting. Clin Child Fam Psychol Rev 2010; 13(2): 164-80.

[http://dx.doi.org/10.1007/s10567-010-0066-z] [PMID: 20390356]

[20] Petch J, Halford WK. Psycho-education to enhance couples' transition to parenthood. Clin Psychol Rev 2008; 28(7): 1125-37. [http://dx.doi.org/10.1016/j.cpr.2008.03.005] [PMID: 18472200]

[21] Lovejoy MC, Graczyk PA, O'Hare E, Neuman G. Maternal depression and parenting behavior: A meta-analytic review. Clin Psychol Rev 2000; 20(5): 561-92.

[http://dx.doi.org/10.1016/S0272-7358(98)00100-7] [PMID: 10860167]

[22] Sarason IG, Sarason BR, Shearin EN, Pierce GR. A brief measure of social support: Practical and theoretical implications. J Soc Pers Relat 1987; 4(4): 497-510.

[http://dx.doi.org/10.1177/0265407587044007]

[23] Abdul Kadir NB, Bifulco A. Insecure attachment style as a vulnerability factor for depression: Recent findings in a communitybased study of Malay single and married mothers. Psychiatry Res 2013; 210(3): 919-24.

[http://dx.doi.org/10.1016/j.psychres.2013.08.034] [PMID: 24075307]

[24] Respler-Herman M, Mowder BA, Yasik AE, Shamah R. Parenting beliefs, parental stress, and social support relationships. J Child Fam Stud 2012; 21(2): 190-8.

[http://dx.doi.org/10.1007/s10826-011-9462-3]

[25] Muzik M, Rosenblum K, Alfafara EA, et al. Mom Power: preliminary outcomes of a group intervention to improve mental health and parenting among high-risk mothers. Archives of women's mental health 2015 ; $18(3)$ : 507-21.

[26] Suzuki S. the effects of marital support, social network support, and 
parenting stress on parenting: self-efficacy among mothers of young children in Japan. J Early Child Res 2010; 8(1): 40-66.

[http://dx.doi.org/10.1177/1476718X09345506]

[27] Eckshtain D, Marchette L K, Schleider J, Weisz J R. Parental depressive symptoms as a predictor of outcome in the treatment of child depression. 2017.

[28] Azeem MW, Dogar IA, Shah S, et al. Anxiety and depression among parents of children with intellectual disability in Pakistan. J Can Acad Child Adolesc Psychiatry 2013; 22(4): 290-5. [PMID: 24223048]

[29] Weitlauf AS, Vehorn AC, Taylor JL, Warren ZE. Relationship satisfaction, parenting stress, and depression in mothers of children with autism. Autism 2014; 18(2): 194-8. [http://dx.doi.org/10.1177/1362361312458039] [PMID: 22987895]

[30] Norizan A, Shamsuddin K. Predictors of parenting stress among Malaysian mothers of children with Down syndrome. J Intellect Disabil Res 2010; 54(11): 992-1003.

[http://dx.doi.org/10.1111/j.1365-2788.2010.01324.x] [PMID: 20868445]

[31] Hayes SA, Watson SL. The impact of parenting stress: A metaanalysis of studies comparing the experience of parenting stress in parents of children with and without autism spectrum disorder. J Autism Dev Disord 2013; 43(3): 629-42.

[http://dx.doi.org/10.1007/s10803-012-1604-y] [PMID: 22790429]

[32] Benson PR. Longitudinal effects of educational involvement on parent and family functioning among mothers of children with ASD. Res Autism Spectr Disord 2015; 11: 42-55.

[http://dx.doi.org/10.1016/j.rasd.2014.11.011]

[33] Strauss K, Mancini F, Fava L. Parent inclusion in early intensive behavior interventions for young children with ASD: A synthesis of meta-analyses from 2009 to 2011. Res Dev Disabil 2013; 34(9): 2967-85.

[http://dx.doi.org/10.1016/j.ridd.2013.06.007] [PMID: 23816632]

[34] Roberts J, et al. A randomised controlled trial of two early intervention programs for young children with autism: Centre-based with parent program and home-based. Res Autism Spectr Disord 2011; 5(4): 1553-66.

[http://dx.doi.org/10.1016/j.rasd.2011.03.001]

[35] Rivard M, Terroux A, Mercier C. Effectiveness of early behavioral intervention in public and mainstream settings: The case of preschoolage children with autism spectrum disorders. Res Autism Spectr Disord 2014; 8(9): 1031-43.

[http://dx.doi.org/10.1016/j.rasd.2014.05.010]
[36] Ilias K, Liaw JHJ, Cornish K, Park MS-A, Golden KJ. Wellbeing of mothers of children with 'A-U-T-I-S-M' in Malaysia: An interpretative phenomenological analysis study. J Intellect Dev Disabil 2017; 42(1): 74-89.

[http://dx.doi.org/10.3109/13668250.2016.1196657]

[37] Kwok SY, Wong D. Mental health of parents with young children in Hong Kong: The roles of parenting stress and parenting self-efficacy. Child and Family Social Work 2000; 5(1): 57-65.

[http://dx.doi.org/10.1046/j.1365-2206.2000.00138.x]

[38] Humphreys KL, King LS, Choi P, Gotlib IH. Maternal depressive symptoms, self-focus, and caregiving behavior. J Affect Disord 2018; 238(May): 465-71.

[http://dx.doi.org/10.1016/j.jad.2018.05.072] [PMID: 29929156]

[39] Inventory P. Inventory for measuring depression. 2018; pp. 561-71.

[40] Fatt Q K, Yun L W, Razack A H, Sin L C. Reliability and validity of the malay version of Beck Depression Inventory (BDI) among urological patients Study sample. Malaysian J Psychiatry 2001; 9: 1-5.

[41] Smith M. Measures for assessing parenting in research and practice. Child Adolesc Ment Health 2011; 16(3): 158-66.

[http://dx.doi.org/10.1111/j.1475-3588.2010.00585.x] [PMID: 32847235]

[42] Tiwari A, Self-Brown S, Lai BS, McCarty C, Carruth L. Effects of an evidence-based parenting program on biobehavioral stress among atrisk mothers for child maltreatment: A pilot study. Soc Work Health Care 2018; 57(3): 137-63.

[http://dx.doi.org/10.1080/00981389.2017.1371096] 28891758]

[43] Acquah D, Sellers R, Stock L, Harold G. Inter-parental conflict and outcomes for children in the contexts of poverty and economic pressure 2017; 1-79.

[44] World Federation For Mental Health (WFMH). Depression: A global crisis. World Ment. Heal. Day 2012; p. 32.

[45] Davé S, Petersen I, Sherr L, Nazareth I. Incidence of maternal and paternal depression in primary care: A cohort study using a primary care database. Arch Pediatr Adolesc Med 2010; 164(11): 1038-44. [http://dx.doi.org/10.1001/archpediatrics.2010.184] [PMID: 20819960]

[46] Neppl T K, Senia J M, Donnelan M B. The effects of economic hardship: Testing the family stress model over time. Fam Psychol 2016; 8(30): 12-21.

[47] Garber J. Evidence-based interventions for depressed mothers and their young children 2017; 88(2): 368-77.

\section{(C) 2021 Yakub et al.}

This is an open access article distributed under the terms of the Creative Commons Attribution 4.0 International Public License (CC-BY 4.0), a copy of which is available at: https://creativecommons.org/licenses/by/4.0/legalcode. This license permits unrestricted use, distribution, and reproduction in any medium, provided the original author and source are credited. 